\title{
Plasma Preparation Tube
}

National Cancer Institute

\section{Source}

National Cancer Institute. Plasma Preparation Tube. NCI Thesaurus. Code C153167.

An evacuated blood collection tube that contains an inert gel and spray-dried K2EDTA

anticoagulant, intended for the collection of whole blood and the separation of plasma. 